New Ent ry to

1, 4, 5, 6- Tet r ahydr o- 2H I ndol - 2-Ones Usi ng a Cat i oni $\mathrm{c}$ 5-Endo- Tri gonal Cycl i zat i on Ont o Enami des

\begin{tabular}{|l|l|}
\hline 著者 & $\begin{array}{l}\text { I shi bashi H royuki, Hi guchi Nasahi ro, Nasuko } \\
\text { H rom, Kodama Kazuya, I keda Nasazumi }\end{array}$ \\
\hline $\begin{array}{l}\text { j our nal or } \\
\text { publ i cat i on ti t l e }\end{array}$ & Het er ocycl es \\
\hline vol une & 46 \\
\hline page r ange & $37-40$ \\
\hline year & 1997- 01- 01 \\
\hline URL & ht t p: //hdl . handl e. net /2297/3279 \\
\hline
\end{tabular}




\title{
NEW ENTRY TO 1,4,5,6-TETRAHYDRO-2H-INDOL- 2-ONES USING A CATIONIC 5-ENDO-TRIGONAL CYCLIZATION ONTO ENAMIDES $\dagger$
}

\author{
Hiroyuki Ishibashi, ${ }^{1 *}$ Masahiro Higuchi, ${ }^{1}$ Hiromi Masuko, ${ }^{2}$ Kazuya \\ $\mathrm{Kodama}^{2}{ }^{2}$ and Masazumi Ikeda ${ }^{2}$ \\ 1 Faculty of Pharmaceutical Sciences, Kanazawa University, Takara-machi, \\ Kanazawa 920, Japan and ${ }^{2}$ Kyoto Pharmaceutical University, Misasagi, \\ Yamashina, Kyoto 607, Japan
}

\begin{abstract}
A new method for the synthesis of 1,4,5,6-tetrahydro- $2 \mathrm{H}$ indol-2-ones by means of 5-endo-trigonal cyclization of $\alpha$-thiocarbocations generated from sulfoxide (12) and $\alpha$-chlorosulfide (17) is described. The sulfoxide (12), upon heating with $\mathrm{TsOH}$, gave 14, which eliminated benzenethiol to give tetrahydroindolone (15). By contrast, the chlorosulfide (17), upon treatment with $\mathrm{TiCl}_{4}$, gave the desulfurized tetrahydroindolone (18). The mechanism for the formation of 18 is also discussed.
\end{abstract}

1,4,5,6-Tetrahydro- $2 H$-indol-2-ones are useful intermediates for the synthesis of several types of Amaryllidaceae alkaloids. For examples, the $N$-(arylmethyl) derivatives $(\mathbb{1}: \mathrm{n}=1)$ having a bromine or iodine atom on the ortho position of the aromatic ring, when subjected to the Heck reaction conditions or to the $\mathrm{Bu}_{3} \mathrm{SnH}$-mediated radical cyclization conditions, give the lycorine skeletons (2), ${ }_{1}^{1}$ and the $N$-(2arylethyl) congeners $(\mathbb{1}: \mathrm{n}=2)$ having electron-donating 3,4-dimethoxy groups on the aromatic ring, when treated with organic acids, provide the erythrinan skeletons (3). ${ }^{1 a}, 2$ Herein we report a new entry to 1,4,5,6-tetrahydro- $2 H$-indol-2-ones using a 5-endo-trigonal cyclization of $\alpha$-thiocarbocations ${ }^{3}$ as a key step.

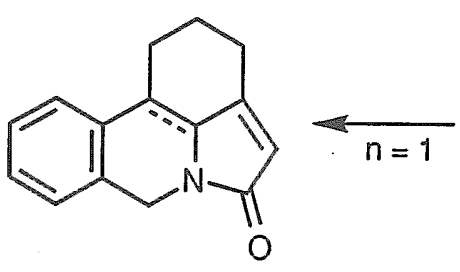

2

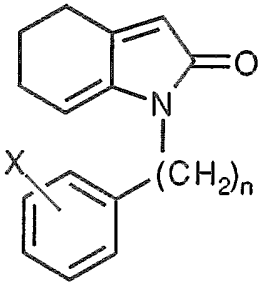

1

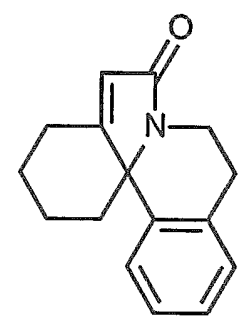

3

$\dagger$ This paper is dedicated to the memory of Professor Emeritus Shun-ichi Yamada (Univeristy of Tokyo). 
Our approach to the synthesis of tetrahydroindolones is outlined in the following Scheme. The key step is the 5-endo-trigonal cyclization of the $\alpha$-thiocarbocations (4) which provides the acyliminium ion intermediates (5). This step is then followed by an elimination of benzenethiol to give 1,4,5,6-tetrahydro3-methylthio-2 $H$-indol-2-ones (6). The $\alpha$-thiocarbocations (4) can be easily derived from the corresponding sulfoxides or $\alpha$-chlorosulfides.<smiles>CSCC(=O)NC1=C([Sb]c2ccccc2)CCCC1</smiles>

4

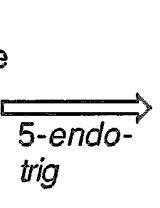

5<smiles>CC1C(=O)N=C2CCCCC21c1ccccc1</smiles>

5<smiles></smiles>

6

We initiated our investigation by examining the cyclization of the sulfoxide (12) under the Pummerer rearrangement conditions. The synthesis of 12 was begun by condensation of 2-(phenylthio)cyclohexanone (7) with $o$-bromobenzylamine (8) followed by $N$-acylation of the resulting imine (9) with bromoacetyl bromide to give the bromoacetamide (10) in $70 \%$ yield (based on 7 ). Treatment of 10 with sodium methylmercaptide gave, in $80 \%$ yield, the sulfide (11), which was oxidized by slow addition of $m$ CPBA to give the sulfoxide (12) in $60 \%$ yield along with the disulfoxide (13) (21\% yield).<smiles>O=C1CCCCC1[SeH]</smiles>

7 (1)<smiles>CC=CCc1ccccc1Br</smiles>

toluene reflux<smiles></smiles>

9

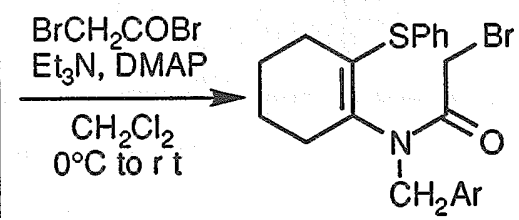

10

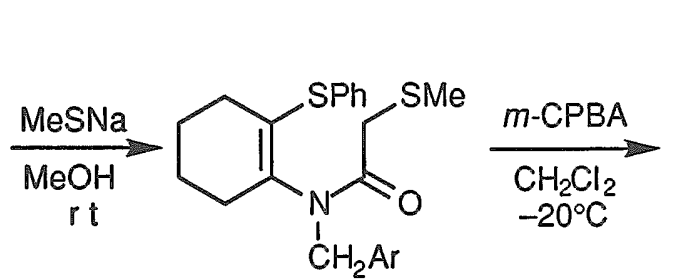

11<smiles>CO[AsH](C)CC(=O)N(C)C1=C([SbH])CCCC1</smiles>

12

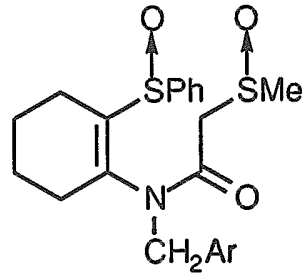

13

Ar $=0$-Bromophenyl

Heating the sulfoxide (12) in boiling 1,2-dichloroethane in the presence of a stoichiometric amount of TsOH for 5 min gave the hexahydroindolone (14) and the tetrahydroindolone (15) 4 in 42 and $36 \%$ yields, respectively. The ${ }^{1} \mathrm{H}-\mathrm{NMR}$ spectrum of $\mathbf{1 4}$ showed it to be a mixture of two diastereoisomers (cis and trans relationships between the phenylthio and the methylthio groups) in a ratio of $c a .2: 1$. The formation of $\mathbf{1 5}$ appears to be the result of an acid-catalyzed elimination of benzenethiol from the initial cyclization 
product (14). Indeed, when the period of heating of 12 was extended up to 30 min, the tetrahydroindolone (15) was obtained as a sole product in $65 \%$ yield.

On the other hand, heating the disulfoxide (13) in the presence of $\mathrm{TsOH}$ (1 equiv.) in boiling 1,2dichloroethane for $5 \mathrm{~min}$ gave only the tetrahydroindolone (15) in $60 \%$ yield. A bulky phenylsulfinyl group of the initial cyclization product (16) might be in positions trans to the adjacent methylthio group, and hence a thermal elimination of benzenesulfenic acid appeared to occur rapidly to give $\mathbf{1 5}$.

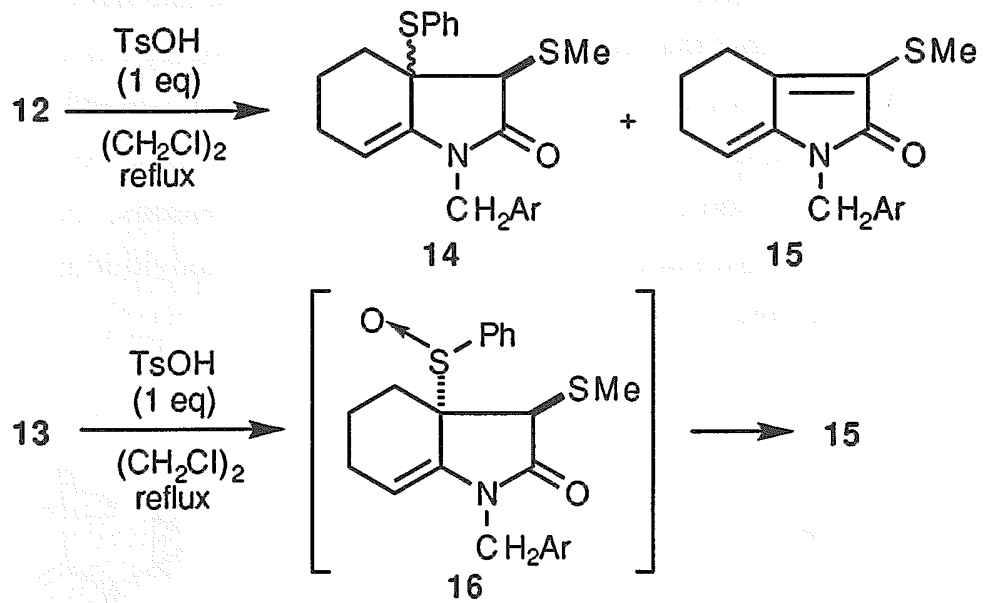

Our attention was next turned to the Lewis acid-promoted cyclization of the chlorosulfide (17), which was prepared (quant.) from the corresponding sulfide (11) by treating with NCS. When the chlorosulfide (17) was exposed to a stoichiometric amount of $\mathrm{TiCl}_{4}$ in $\mathrm{CH}_{2} \mathrm{Cl}_{2}$ at room temperature for $1 \mathrm{~h}$, two indolone derivatives were obtained. One of them was the compound (14) (30\% yield: a ca. 5:1 mixture of two diastereoisomers) which was identical to that obtained from 12. Interestingly, another one was proven to be an unexpected product (18) (34\% yield). The ${ }^{1} \mathrm{H}-\mathrm{NMR}$ spectrum of 18 exhibited the signals at $\delta 5.51$ (dt, $J=1.7,4.7 \mathrm{~Hz}$ ) and $\delta 5.85$ (br s) due to the olefinic protons at the C7 and C3 positions, respectively.

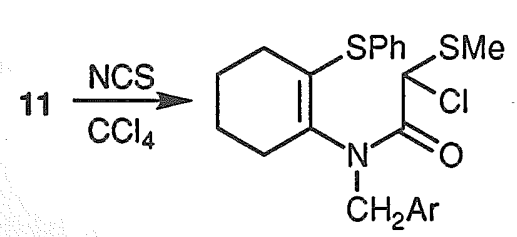

17

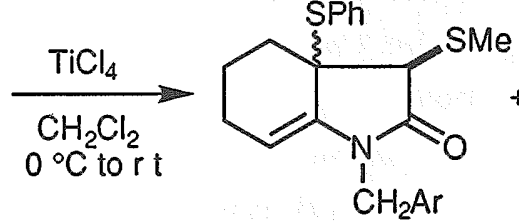

14<smiles>CCN1C(=O)C=C2CCCC=C21</smiles>

18<smiles>CC1=C2CCCCC2(P)N(C(=O)C(C)C)C1=O</smiles> 
In order to see the mechanism for the formation of 18 (probably from 14), several experimentations were carried out with $\mathrm{TiCl}_{4}$ and $\mathrm{HCl}$ gas, the latter of which might arise during the formation of 14 from 17. When compound (14) was treated either with a stoichiometric amount of $\mathrm{TiCl}_{4}$ or with $\mathrm{HCl}$ gas in $\mathrm{CH}_{2} \mathrm{Cl}_{2}$ at room temperature, only the starting material was recovered unchanged. However, treatment of 14 with $\mathrm{TiCl}_{4}$ in the presence of $\mathrm{HCl}$ gas gave 18 in $29 \%$ yield together with an additional product (19) (30\% yield). The structure of 19 was deduced from its ${ }^{1} \mathrm{H}-\mathrm{NMR}$ spectrum ${ }^{4}$ and its chemical transformation: heating 19 with $\mathrm{TsOH}$ in benzene afforded 15 in $60 \%$ yield. One possible rationalization for the formation of 18 is based on the assumption that the methylthio group at the $C 3$ position of the trans-isomer of 14 coordinates to $\mathrm{TiCl}_{4}$ to give the sulfonium ion intermediate (20), and then the anti-elimination occurs by an attack of the chloride ion (derived from $\mathrm{HCl}$ ) on the phenylthio group to give 18. This type of reaction, however, is inapplicable to the cis-isomer of $\mathbf{1 4}$ for the stereoelectronic reasons, and hence the cis-isomer is merely protonated to give the acyliminium intermediate (21). The phenylthio group of 21 undergoes 1,2 -migration through the episulfonium salt 22 to give the observed 19.5
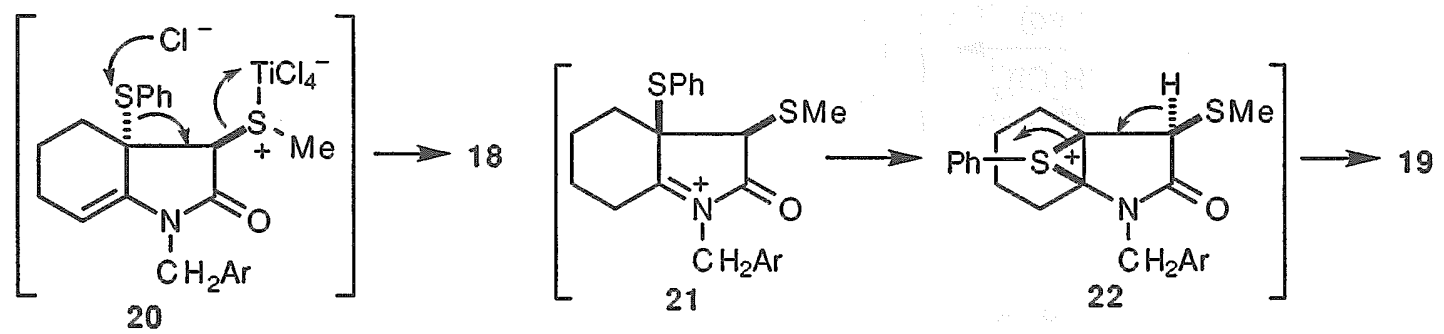

Thus we revealed that the 5-endo-trigonal cyclization of $\alpha$-thiocarbocations generated from the sulfoxide (12) and the chlorosulfide (17) provided a new method for the synthesis of a different type of $1,4,5,6-$ tetrahydro- $2 \mathrm{H}$-indol-2-ones such as $\mathbf{1 5}$ and $\mathbf{1 8}$. An application of the method to the synthesis of lycorine and erythrina alkaloids will be reported in due course.

\section{REFERENCES AND NOTES}

1. (a) J. H. Rigby and M. Qabar, J. Am. Chem. Soc., 1991, 113, 8975; (b) J. H. Rigby, R. C. Hughes, and M. J. Heeg, J. Am. Chem. Soc., 1995, 117, 7834; (c) J. H. Rigby and M. E. Mateo, Tetrahedron, 1996, 52, 10569.

2. A. Mondon, J. Zander, and H.-U. Menz, Liebigs Ann. Chem., 1963, 667, 126.

3. Y. Tamura, H. Maeda, S. Akai, and H. Ishibashi, Tetrahedron Lett., 1982, 23, 2209; H. Ishibashi, K. Sato, M. Ikeda, H. Maeda, S. Akai, and Y. Tamura, J. Chem. Soc., Perkin Trans. 1, 1985, 605; H. Ishibashi and M. Ikeda, Rev. Heteroatom Chem., 1992, 7, 191.

4. ${ }^{1} \mathrm{H}-\mathrm{NMR}$ for $15\left(300 \mathrm{MHz}, \mathrm{CDCl}_{3}\right): \delta 1.83$ (quint, $\left.J=6.1 \mathrm{~Hz}, 2 \mathrm{H}\right), 2.28$ (q, $\left.J=6.1 \mathrm{~Hz}, 2 \mathrm{H}\right), 2.55$ $(\mathrm{s}, 3 \mathrm{H}), 2.66(\mathrm{t}, J=6.5 \mathrm{~Hz}, 2 \mathrm{H}), 4.84(\mathrm{~s}, 2 \mathrm{H}), 6.46(\mathrm{t}, J=4.7 \mathrm{~Hz}, 2 \mathrm{H}), 6.95-7.55(\mathrm{~m}, 4 \mathrm{H})$. For 19: $\delta 1.2-3.0(\mathrm{~m}, 8 \mathrm{H}), 2.53(\mathrm{~s}, 3 \mathrm{H}), 4.71(\mathrm{~d}, J=15.6 \mathrm{~Hz}, 1 \mathrm{H}), 4.98(\mathrm{~d}, J=15.6 \mathrm{~Hz}, 1 \mathrm{H}), 7.05-$ $7.60(\mathrm{~m}, 9 \mathrm{H})$.

5. It seems reasonable to assume that the reaction of $\mathbf{1 7}$ giving $\mathbf{1 4}$ and $\mathbf{1 8}$ provides also the compound 19, but no corroborating evidence for this assumption is offered at the moment. 